\title{
Neurological diagnoses in the emergency room Differences between younger and older patients
}

\author{
Marcos C. Lange, Vera L. Braatz, Carolina Tomiyoshi, Felipe M. Nóvak, \\ Artur F. Fernandes, Laura N. Zamproni, Élcio J. Piovesan, \\ Edison M. Nóvak, Helio A.G. Teive, Lineu C. Werneck
}

\begin{abstract}
Neurological diseases are prevalent in the emergency room (ER). The aim of this study was to compare the neurological diagnoses between younger and older patients evaluated in the ER of a tertiary care hospital. Method: Patients admitted to the ER who required neurological evaluation in the first 24 hours were separated into two groups based on age, $\leq 50$ years old and $>50$ years old. Results: Cerebrovascular disease $(59.6 \%$ vs. $21.8 \%$, $p<0.01)$ was most frequent in the $>50$ years old group. Seizures $(8.1 \%$ vs. $18.6 \%, p<0.01)$ and primary headache $(3.7 \%$ vs. $11.4 \%, p<0.01)$ were most frequent in the $\leq 50$ years old group. Conclusion: The current study demonstrated that these three neurological diagnoses represented the majority of the neurological evaluations in the ER. National guidelines for ER teams that treat these prevalent disorders must be included in clinical practice and training.

Key words: nervous-system disease, stroke, headache, seizures, emergency medical services, health services epidemiology.
\end{abstract}

Diagnósticos neurológicos na sala de emergência: diferenças entre pacientes jovens e idosos

\section{RESUMO}

Doenças neurológicas são prevalentes na sala de emergência (SE). O objetivo deste estudo é comparar a ocorrência de diagnósticos neurológicos entre pacientes jovens e idosos atendidos na SE de um hospital terciário. Método: Pacientes admitidos na SE que necessitaram avaliação neurológica nas primeiras 24 horas após a admissão foram separados em dois grupos baseados na idade, $\leq 50$ anos de idade e $>50$ anos de idade. Resultados: Doença cerebrovascular foi o diagnóstico mais comum nos pacientes $>50$ anos $(59,6 \%$ vs. $21,8 \%, p<0,01)$. Convulsões $(8,1 \%$ vs. $18,6 \%, p<0,01)$ e cefaléias primárias $(3,7 \%$ vs. $114 \%, p<0,01)$ foram mais frequentes no grupo $\leq 50$ anos. Conclusão: $O$ presente estudo demonstrou que esses três diagnósticos neurológicos representam a maioria das avaliações neurológicas na SE. Diretrizes nacionais para os profissionais emergencistas que tratam estas doenças devem ser incluídos na prática clínica e no treinamento médico. Palavras-chave: doença do sistema nervoso, AVC, cefaléia, convulsões, serviço médico de emergência, epidemiologia em serviços de saúde.

\section{Correspondence \\ Marcos Christiano Lange Hospital de Clínicas Serviço de Neurologia Rua General Carneiro $181 / 4^{\circ}$ andar 80060-900 Curitiba PR - Brasil E-mail: lange@ufpr.br}

Received 10 May 2010 Received in final form 17 August 2010 Accepted 24 August 2010
In recent years, with technological improvement and new methods of therapeutic management, emergency medicine has become an important medical specialty. Patients evaluated in the emergency room (ER) could have life-threat- ening diseases that must be identified immediately to begin the correct treatment and improve patient prognosis. Neurological disorders are a common reason for admission to the ER and are associated with high morbidity and mortality, 
increasing public-health costs ${ }^{1}$. From $8 \%$ to $15 \%$ of all patients admitted to the ER in general hospitals require assessment by a neurologist ${ }^{2}$.

Generally, cerebrovascular disease (CVD), headache and epilepsy accounted for almost half of all acute admissions related to neurological diseases ${ }^{3}$, and elderly patients had the highest incidence of neurological symptoms during ER evaluation ${ }^{2}$.

In Brazil, there is little information available on the characteristics of the neurological consultation that takes place in the ER. The aim of this study was to evaluate the clinical profile and short-term follow-up of patients admitted to the ER of a university hospital and to compare young and old patients in an attempt to identify different patterns.

\section{METHOD}

A retrospective review of the data bank from the Emergency Neurology Unit of the Neurology Division of the Hospital de Clínicas at the Universidade Federal do Paraná (HC-UFPR) was done. The ER of the HC-UFPR is a tertiary care, nontrauma reference unit, exclusively dedicated to public-health assistance. The clinical neurological staff of the hospital is on call 24 hours a day, 7 days a week. The study was approved by the Local Ethics Committee of the institution.

All patients admitted to the ER of the HC-UFPR who required neurological assessment from February 2007 to January 2008 were evaluated. Inclusion criteria for the study were patients older than 14 years with acute neurological symptoms, evaluated by the ER staff and by the hospital neurologist in the 24 hours following admission. Exclusion criteria were nonemergency patients and patients without data on the medical registers to confirm the patient's diagnosis and outcome.

The data evaluated were gender, age, main diagnosis and outcome (discharge or hospital admission and death). Only deaths that occurred in the first 72 hours after ER admission were considered to be related. All patients were submitted to a neurological clinical evaluation and when necessary, laboratory and neurological complementary analyses were performed for determining the final diagnosis, including brain computed tomography, brain magnetic resonance imaging, digital arteriography, cerebrospinal fluid analysis, electroencephalography or electromyography with nerve conduction study that was based on the clinical neurological findings. Patients with previous neurological diseases were included when they presented acute complications or a recent worsening of symptoms. The main diagnoses were categorized into the following disease groups: [A] CVD, confirmed based on brain imaging that was distinct from arterial and venous, hemorrhagic and ischemic stroke conditions. This diagnosis was concluded only for patients with symptom onset within the last 24 hours; [B] A diagnosis of epilepsy was considered when the patient presented with a previous history of seizures and was admitted because of convulsive symptoms within the last 6 hours; or if the patient presented with first-ever seizures within the past 24 hours without secondary findings after clinical, neurological and complementary evaluation, excluding a secondary seizure; [C] Primary headache was considered when the patient presented with a previous history of primary headache with symptoms worsening within the past 24 hours; or if clinical, neurological and complementary evaluation excluded secondary causes for the symptoms in a patient without a previous headache history; [D] Neurological symptoms secondary to clinical condition (SCC) were considered when the neurological symptoms were related to clinical diseases due to systemic infection or disturbances in metabolic, cardiac, endocrine or other systems that were confirmed by complementary methods; [E] Central nervous system (CNS) infection was considered when clinical, neurological and complementary diagnosis confirmed acute meningitis, encephalitis or brain abscess. This group included patients with CNS infections that were secondary to HIV/AIDS.

All of the other disorders identified during the period of study and evaluated by the neurologist within the first 24 hours after ER admission were based on the current clinical guidelines and expertise of the neurologist. They included psychiatric conditions, neuromuscular disorders, demyelinating disease, movement disorder, CNS neoplasm, spinal cord acute disease, unspecified isolated cranial nerve palsy and other less common neurological conditions.

After diagnosis evaluation, patients were separated in two age groups, a younger group ( $\leq 50$ years old) and an older group ( $>50$ years old) to identify the main diagnosis and outcome.

The statistical analysis was performed with SPSS 12.0 software (SPSS Inc.). Statistical significance was assessed by a Student's t-test for the parametric variables, and the chi-square and Mann-Whitney tests were used for the non-parametric variables. Statistical significance was determined at $\mathrm{p}<0.05$.

\section{RESULTS}

Of 8723 patients admitted to the ER of the HCUFPR in the study period, 937 (10.7\%) were evaluated by the neurology staff. Data forms were completed in $780(83.2 \%)$ of the cases. Incomplete information in the data bank excluded the other 157 (16.8\%) patients from the study analysis.

Of the 780 patients, 410 (52.5\%) were female, and 
Table 1. Main neurological diagnoses and clinical outcomes for 780 patients evaluated by the neurology staff in the ER.

\begin{tabular}{|c|c|c|c|c|c|c|c|c|c|c|c|}
\hline \multirow[b]{2}{*}{ Diagnosis } & \multicolumn{2}{|c|}{ No. of cases } & \multicolumn{2}{|c|}{ Gender } & \multirow[b]{2}{*}{ Mean age $\pm S D$} & \multicolumn{2}{|c|}{ Discharge } & \multicolumn{2}{|c|}{ Admission } & \multicolumn{2}{|c|}{ Deaths } \\
\hline & $\mathrm{n}$ & $\%$ & Female & Male & & $\mathrm{n}$ & $\%$ & $\mathrm{n}$ & $\%$ & $\mathrm{n}$ & $\%$ \\
\hline CVD & 333 & 42.69 & 163 & 170 & $61.45 \pm 15.19$ & 104 & 31.23 & 229 & 68.77 & 24 & 7.21 \\
\hline Epilepsy/seizure & 100 & 12.82 & 52 & 48 & $43.31 \pm 19.64$ & 63 & 63 & 37 & 37.00 & 0 & - \\
\hline SCC & 63 & 8.08 & 25 & 38 & $59.47 \pm 16.86$ & 32 & 50.79 & 31 & 49.21 & 2 & 3.17 \\
\hline Primary headache & 56 & 7.18 & 37 & 19 & $39.57 \pm 16.08$ & 51 & 91.07 & 5 & 8.93 & 0 & - \\
\hline CNS infection & 42 & 5.38 & 17 & 25 & $40.95 \pm 18.81$ & 4 & 9.52 & 38 & 90.48 & 2 & 4.76 \\
\hline Psychiatric condition & 30 & 3.85 & 24 & 6 & $39.30 \pm 16.27$ & 27 & 90 & 3 & 10.00 & 0 & - \\
\hline Neuromuscular disease & 29 & 3.72 & 15 & 14 & $43.86 \pm 14.87$ & 8 & 27.59 & 21 & 72.41 & 0 & - \\
\hline Demyelinating disease & 29 & 3.72 & 23 & 6 & $33.00 \pm 13.55$ & 14 & 48.28 & 15 & 51.72 & 0 & - \\
\hline Movement disorders & 28 & 3.59 & 17 & 11 & $45.82 \pm 20.45$ & 13 & 46.43 & 15 & 53.57 & 0 & - \\
\hline CNS neoplasm & 23 & 2.95 & 13 & 10 & $56.60 \pm 14.38$ & 5 & 21.74 & 18 & 78.26 & 1 & 4.35 \\
\hline Unspecified isolated cranial nerve palsy & 14 & 1.79 & 7 & 7 & $55.57 \pm 18.03$ & 13 & 92.86 & 1 & 7.14 & 0 & - \\
\hline Spinal cord acute disease & 12 & 1.54 & 6 & 6 & $57.41 \pm 18.18$ & 3 & 25 & 9 & 75.00 & 0 & - \\
\hline Others & 21 & 2.69 & 11 & 10 & $51.38 \pm 19.42$ & 10 & 47.62 & 11 & 52.38 & 1 & 4.76 \\
\hline Total & 780 & - & 410 & 370 & - & 347 & 44.48 & 433 & 55.51 & 30 & 3.84 \\
\hline
\end{tabular}

n: number of cases; CVD: cerebrovascular diseases; SCC: secondary to clinical condition; CNS: central nervous system.

the mean age was $52.5 \pm 19.1$ years of age. CVD was the most common main diagnosis, and it was identified in 333 (42.6\%) patients; 163 (48.9\%) of these patients were female, and the mean age was $61.4 \pm 15.1$ years of age. From this group, 245 (73.5\%) cases were due to ischemic stroke, 83 (25\%) were due to hemorrhagic stroke and five (1.5\%) were due to cerebral venous thrombosis.

The second most common main diagnosis was seizures, which presented in 100 (12.8\%) patients; the mean age was $43.3 \pm 19.6$ with $52(52 \%)$ patients being female. Neurological symptoms SCC were the third most common diagnosis, presenting in 63 (8\%) of the patients; the mean age was $59.4 \pm 16.8$, and 25 (39.6\%) were female. Primary headache was observed in $56(7.2 \%)$ of the patients; the mean age was $39.5 \pm 16.0$, and 37 (66\%) were female. These four previous diseases presented in $70.7 \%$ of all patients evaluated, and only CVD, seizures and headache were observed in $62.6 \%$ of all cases. The diagnoses are shown in Table 1.

Of the 780 patients, 433 (55.6\%) were admitted to the hospital for medical treatment, and 347 (44.4\%) were discharged within the first 24 hours after ER evaluation. Of all patients, 30 (3.8\%) died in the first three days after neurological evaluation. The most frequent cause of death was CVD, which occurred in 24 patients and represented $80 \%$ of all deaths in the study group.

When the patients were separated into two groups based on age; the younger group consisted of 349 (44.7\%) patients with a mean age of $34.9 \pm 10.6$, and 195 (55.9\%) were female. The other 431 (55.3\%) patients made up the older group, with a mean age of $66.8 \pm 10.6$, and 215
(49.9\%) were female. There was no statistical difference between both groups based on gender $(\mathrm{p}=0.96)$.

CVD was the most common disease in both groups but was more prevalent in the older group compared with the younger group [257 (59.6\%) vs. 76 (21.8\%), $\mathrm{p}<0.01]$. When only the arterial ischemic stroke patients was considered, 50 (14.3\%) cases occurred in the younger group and 195 (45.2\%) in the older group ( $\mathrm{p}<0.01)$. Neurological symptoms SCC were more common in the older group (10.6\%) compared with the younger group (4.8\% $\mathrm{p}<0.01)$.

In contrast with CVD, the incidence of seizures was almost three times more frequent in the younger group $(65,18.6 \%)$ than in the older group $(35,8.1 \%$; $<<0.01)$, and primary headache was almost four times more frequent in the younger group $(40,11.4 \%)$ than in the older group (16, 3.7\%; $\mathrm{p}<0.01)$. All the etiologies are presented in Table 2.

Hospital admission occurred in 182 (52.1\%) patients from the younger group and 251 (58.2\%) patients from the older group $(p=0.08)$. In both groups, $C V D$ was the main clinical indication on hospital admission, $63(34.6 \%)$ in the younger group and $166(66.1 \%)$ in the older group ( $\mathrm{p}<0.01)$. Except for CVD, all other admissions were similar in both groups (Table 2).

From the younger group, nine (2.5\%) patients died in the first three days after admission. Eight (89\%) died from secondary causes due to CVD and one from secondary causes due to a CNS neoplasm. In the older group, $21(4.8 \%)$ patients died, $16(76.2)$ were due to secondary CVD causes, two to neurological symptoms 
Table 2. Diagnosis, hospital admission and deaths based on the age groups.

\begin{tabular}{|c|c|c|c|c|c|c|c|c|c|c|c|c|c|}
\hline & \multicolumn{2}{|c|}{ Diagnosis } & \multirow[b]{3}{*}{$p$} & \multicolumn{4}{|c|}{ Admissions } & \multirow[b]{3}{*}{$p$} & \multicolumn{4}{|c|}{ Deaths } & \multirow[b]{3}{*}{$p$} \\
\hline & \multirow{2}{*}{$\frac{\leq 50 \text { yo }}{n}$} & \multirow{2}{*}{$\frac{>50 \text { yo }}{n}$} & & \multicolumn{2}{|c|}{$\leq 50$ yo } & \multicolumn{2}{|c|}{$>50$ yo } & & \multicolumn{2}{|c|}{$\leq 50$ yo } & \multicolumn{2}{|c|}{$>50$ yo } & \\
\hline & & & & $n$ & $\%$ & $n$ & $\%$ & & $n$ & $\%$ & $n$ & $\%$ & \\
\hline CVD & 76 & 257 & $<0.01$ & 63 & 82.9 & 166 & 64.6 & 0.002 & 8 & 10.5 & 16 & 6.2 & 0.21 \\
\hline Epilepsy/seizure & 65 & 35 & $<0.01$ & 20 & 30.8 & 17 & 48.6 & 0.07 & 0 & 0.0 & 0 & 0.0 & - \\
\hline SCC & 17 & 46 & $<0.01$ & 6 & 35.3 & 25 & 54.3 & 0.25 & 0 & 0.0 & 2 & 4.3 & 1.00 \\
\hline Primary headache & 40 & 16 & $<0.01$ & 4 & 10.0 & 1 & 6.3 & 1.00 & 0 & 0.0 & 0 & 0.0 & - \\
\hline CNS infection & 34 & 8 & $<0.01$ & 30 & 88.2 & 8 & 100.0 & 0.57 & 0 & 0.0 & 2 & 25.0 & 0.03 \\
\hline Psychiatric condition & 23 & 7 & $<0.01$ & 2 & 8.7 & 1 & 14.3 & 1.00 & 0 & 0.0 & 0 & 0.0 & - \\
\hline Neuromuscular disease & 20 & 9 & 0.01 & 17 & 85.0 & 4 & 44.4 & 0.06 & 0 & 0.0 & 0 & 0.0 & - \\
\hline Demyelinating disease & 25 & 4 & $<0.01$ & 13 & 52.0 & 2 & 50.0 & 1.00 & 0 & 0.0 & 0 & 0.0 & - \\
\hline Movement disorders & 18 & 10 & 0.03 & 11 & 61.1 & 4 & 40.0 & 0.43 & 0 & 0.0 & 0 & 0.0 & - \\
\hline CNS neoplasm & 8 & 15 & 0.39 & 6 & 75.0 & 12 & 80.0 & 1.00 & 1 & 12.5 & 0 & 0.0 & 0.34 \\
\hline Unspecified isolated cranial nerve palsy & 6 & 8 & 1.00 & 1 & 16.7 & 0 & 0.0 & 0.42 & 0 & 0.0 & 0 & 0.0 & - \\
\hline Spinal cord acute disease & 5 & 7 & 1.00 & 3 & 60.0 & 6 & 85.7 & 0.52 & 0 & 0.0 & 0 & 0.0 & - \\
\hline \multirow[t]{2}{*}{ Others } & 12 & 9 & 0.27 & 6 & 50.0 & 5 & 55.6 & 1.00 & 0 & 0.0 & 1 & 11.1 & 0.42 \\
\hline & 349 & 431 & & 182 & & 251 & & & 9 & & 21 & & \\
\hline
\end{tabular}

yo: years old; n: number of cases; CVD: cerebrovascular diseases; SCC: secondary to clinical condition; CNS: central nervous system.

SCC, two secondary to CNS neoplasm and one to an acute progressive encephalopathy. When evaluating only CVD, there was no statistical difference between both groups; for ischemic stroke, 50 (65.8\%) patients were in the younger group vs. 195 (75.9\%) patients in the older group, $\mathrm{p}=0.08$; for hemorrhagic stroke, 23 (30.2\%) patients were in the younger group vs. $60(23.3 \%)$ patients in the older group, $\mathrm{p}=0.22$; and for cerebral venous thrombosis, three (4\%) patients were in the younger group vs. two $(0.8 \%)$ patients in the older group, $\mathrm{p}=0.08$. Ischemic stroke was the cause of death in three (3.9\%) patients from the younger group and in eight (3.1\%) patients from the older group ( $\mathrm{p}=0.70)$, and hemorrhagic stroke was the cause in five $(6.5 \%)$ patients from the younger group and in seven (1.6\%) from the older group $(p=0.29)$. Only one patient in the older group died from cerebral venous thrombosis.

\section{DISCUSSION}

This study demonstrates that almost $11 \%$ of patients in the ER needed a neurological evaluation in the first 24 hours, and the four most common emergency neurological diseases evaluated by a neurologist were stroke, epilepsy, headache and neurological symptoms secondary to clinical conditions. Stroke represented the most frequent diagnosis upon hospital admission and the most prevalent cause of death in the first 72 hours after ER evaluation; these results were independent of the patient's age.

Previous studies demonstrated that neurological complaints were observed in $10 \%$ of all ER evaluations.
Furthermore, from all patients evaluated in the ER, 10\% to $20 \%$ were admitted to the hospital for neurological diagnoses $^{1,2}$. In Brazil, there are no recent data on neurological disorders evaluated in the ER; according to Datasus, of the 933,171 national monthly hospital admissions, 13,696 (1.5\%) were due to neurologic diseases, which accounted for $2.6 \%$ of all deaths $s^{4}$. The morbidity and mortality of neurological complaints should serve as the impetus for neurologic education in emergency departments ${ }^{5}$. In this study, $11 \%$ of all admissions to the ER were related to neurological disorders; this significant proportion should be considered during the training programs for emergency medicine and neurology, with the aim of improving the ability of hospital staff to diagnose and treat this prevalent group of diseases.

There is agreement among previous studies as to the most common causes for neurological evaluation during the ER admission. Carroll and Zajicek showed that stroke, headache and seizures were the three most common ER admissions and accounted for $53 \%$ of cases ${ }^{6}$. Another study also demonstrated that $39 \%$ of hospital admissions after ER evaluation were related to CVD, headache and epilepsy ${ }^{7}$. These results were similar to the data presented in this study, in which CVD and seizures presented in $55 \%$ of the patients evaluated by the neurologist in the ER, and headache increased this number to $63 \%$.

A previous systematic review about stroke in South America demonstrated that the mean age varies between 58 until 67 years of age. The current study confirmed these findings, with a mean age of 61.4 years old. This 
information suggests that patients evaluated in a tertiary ER could present CVD younger than usually, and this could be related to a poor control of risk factor, or even to a higher diagnostic complexity ${ }^{8}$. Improvement in CVD treatment must be undertaken in the ER. Until now, however, this treatment category has been underdeveloped, even in Europe, where only 28\% of neurological centers have stroke units ${ }^{1}$. These units represent the most efficacious model for care provision compared with general ward care and stroke teams, but in Brazil, only few hospitals have them disponible?. Every stroke patient can potentially benefit from care in a stroke unit. These units usually are efficient, cost-effective, and their benefits are consistent over time ${ }^{10}$.

A Canadian cohort showed that initial assessment by a stroke team reduced stroke case fatality at 7 days, 30 days and 1 year ${ }^{11}$. In a Spanish study, stroke presented a mortality rate of $19.6 \%$ in the first month, $23.9 \%$ in three months and $28.8 \%$ in the first year ${ }^{12}$. Some data showed a cumulative mortality risk of $10 \%$ in five years after stroke onset in patients 15 to 49 years old, with a higher incidence among the elderly ${ }^{13}$. According to a Brazilian database of all neurologic patients admitted to hospitals, about $6.5 \% \mathrm{died}^{4}$. Acute stroke protocols improved outcome in ischemic stroke patients when neurology staff and emergency medical services work together ${ }^{14}$. The current study demonstrated higher rates of death in the first 72 hours, possibly because of the high complexity of cases evaluated in our tertiary center. Stroke was the most common cause associated with it, independent of the age group.

The second most frequent condition in the ER in our study was seizures, with predominance of younger patients. Previous study demonstrated that in acute symptomatic seizures, stroke was the most common cause of epilepsy, representing 30\% to $50 \%$ of cases in this group. Other causes included trauma, infection, neoplasm and metabolic abnormalities ${ }^{2}$. Epilepsy is a chronic condition that is best treated in the outpatient clinic setting; however, many patients use the ER as a primary resource for seizure management. The patient who repeatedly uses the ER for management of the chronic condition tends not to follow up in the neurology clinic, and this represents one of the most difficult problems facing epilepsy clinics ${ }^{15}$.

Another important neurologic condition in the ER is headache. In their study on headache in the ER, Gahir and Larner showed that $25 \%$ of the new referrals had the principal complaint of headache, and the median age of these patients was 39 years ${ }^{16}$. Despite the higher incidence in their study, they confirmed that the highest frequency occurred in the younger patients ${ }^{16}$.

Some limitations of this study should be discussed. First, this study included patients admitted to a spe- cialized, tertiary public-health center, and the results were not comparable to those treated at other facilities. Second, the study was retrospective and based on databank information; this could affect some results. Third, the neurological evaluations of admitted patients were entered into the database by a neurologist in the first 24 hours after ER arrival. Whether patients died before evaluation or whether neurological patients were not seen by a neurologist in that short period was not considered.

In conclusion, neurological diseases are very common in the ER, with stroke, seizures and headache being the most frequent complaints. In the tertiary university ER studied, stroke was the main cause of neurological admissions and death, even in patients younger than 50 years old. National guidelines should be incorporated into training programs for ER teams that treat these prevalent disorders. Timely diagnosis and effective treatment options should be emphasized in the Brazilian public-health system to improve the outcomes of affected patients.

\section{REFERENCES}

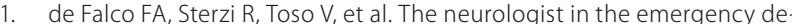
partment: an Italian nationwide epidemiological survey. Neurol Sci 2008; 29:67-75.

2. Waterhouse $E$, Towne A. Seizures in the elderly: nuances in presentation and treatment. Cleve Clin J Med 2005;72:26-37.

3. Moulin T, Sablot D, Vidry E, et al. Impact of emergency room neurologists on patient management and outcome. Eur Neurol 2003;50:207-214.

4. Ministério da Saúde / SVS - DATASUS. Available at http://tabnet datasus. gov.br/cgi/tabcgi.exe?idb2008/c08.def (Indicadores de mortalidade). Accessed (Nov, 22, 2009).

5. Stettler BA, Jauch EC, Kissela B, Lindsell CJ. Neurologic education in emergency medicine training programs. Acad Emerg Med 2005;12:909-911.

6. Carroll C, Zajicek J. Provision of 24 hour acute neurology care by neurologists: manpower requirements in the UK. J Neurol Neurosurg Psychiatry 2004;75:406-409.

7. Olazarán J, Navarro E, Galiano M, et al. Quality of neurological care in the emergency services: a study from the community-hospital. Neurología 2009;24:249-254.

8. Saposnik G, Del Brutto OH. Stroke in South America: a systematic review of incidence, prevalence, and stroke subtypes. Stroke 2003;34:2103-2107.

9. Cabral NL, Moro C, Silva GR, Scola RH, Werneck LC. Study comparing the stroke unit outcome and conventional ward treatment: a randomized study in Joinville, Brazil. Arq Neuropsiquiatr 2003;61:188-193.

10. Fuentes B, Díez-Tejedor E. Stroke units: many questions, some answers. Int J Stroke 2009:4:28-37.

11. Saposnik G, Hill MD, O’Donell M, Fang J, Hachinski V, Kapral MK. Variables associated with 7-day, 30-day, and 1-year fatality after ischemic stroke. Stroke 2008;39:2318-2324

12. Aymerich $\mathrm{N}$, Zandio $\mathrm{B}$, Martin $\mathrm{M}$, et al. Incidencia de ictus y mortalidad precoz en la comarca de Pamplona. Neurología 2007;22:603.

13. Putaala J, Curtze S, Hiltunen S, Tolppanen H, Kaste M, Tatlisumak T. Causes of death and predictors of 5-year mortality in young adults after firstever ischemic stroke: the Helsinki Young Stroke Registry. Stroke 2009;40: 2698-2703.

14. Lange MC, Zetola VF, Parolin MK, et al. University hospital and prehospital service cooperation for thrombolysis in a developing country. Stroke 2009;40:208.

15. Farhidvash F, Singh P, Abou-Khalil B, Arain A. Patients visiting the emergency room for seizures: insurance status and clinic follow-up. Seizure 2009;18:644-647.

16. Gahir KK, Larner AJ. Primary headache disorder in the emergency department: perspective from a general neurology outpatient clinic. Emerg Med J 2006;23:135-136. 